\title{
Impact of Helicobacter pylori Eradication on Absolute Telomere Length in Gastric Mucosa
}

\author{
Maha Z. Omar ${ }^{1}$, Abeer A. Aboelazm ${ }^{2}$, Reem R. Abd El-Glil ${ }^{2}$ \\ ${ }^{1}$ Department of Hepatology, Gastroenterology and Infectious Diseases, Faculty of Medicine, Benha University, Egypt \\ ${ }^{2}$ Medical Microbiology and Immunology, Faculty of Medicine, Benha University, Egypt
}

Corresponding Author Maha Z Omar

Mobile: +2012232873

12

\section{E mail:}

mahazeinelabedin@ya hoo.com

\section{Key words:}

Helicobacter pylori, eradication therapy, absolute telomere length, gastric ulcer.
Background and study aim: This study proposed to assess the relation between absolute telomere lengths (TLs) in gastric mucosa and Helicobacter pylori $(H$. pylori) infection and study the impact of (H. pylori) eradication therapy on TLs.

Patients and Methods: This study was conducted on (42) subjects divided into two groups, group I: included (17) H. pylori negative cases served as control group, group II: included (25) H. pylori positive patients. Absolute TLs was measured in base pairs (bp) in gastric mucosa and analyzed by real time polymerase chain reaction (RT-PCR) in all groups and reevaluated in $H$. pylori positive patients 4 weeks after eradication therapy.

Results: Prior to eradication therapy, there was highly significant shortening $(\mathrm{P}<0.001)$ in TLs $(\mathrm{bp})$ in gastric mucosa of $H$. pylori positive patients compared to H. pylori negative controls. While there was highly significant elongation was observed after $H$. pylori eradication therapy in $\mathrm{H}$. pylori positive patients $(\mathrm{P}<0.001)$. There was significant negative correlation between TLs and ages of patients $(\mathrm{P}<0.001)$ while there was no significant relation between TLs and sex $(\mathrm{P}=0.5)$ before and after eradication therapy.

Conclusion: $H$. pylori positive patients had significantly shorter TLs than $H$. pylori negative controls. TLs were increased after $H$. pylori eradication therapy in $\mathrm{H}$. pylori positive cases. This finding may indicate the importance of $H$. pylori eradication to avoid the development of gastric cancer by its effect on TLs.

\section{INTRODUCTION}

Helicobacter pylori (H. pylori) is a gram- negative, non-invasive, helixshaped, microaerophilic agent. It is the most common chronic bacterial infection in humans. H. pylori infection is strongly related with socioeconomic status and its prevalence is over $80 \%$ in developing countries and $20-50 \%$ in developed countries [1]. H. pylori is the etiological agent of chronic gastritis, peptic ulcer, and has been documented to be linked with the development of gastric adenocarcinoma and lymphoma [2]. Histological pre-neoplastic changes that might progress into gastric cancer are found in around $50 \%$ of people infected with $H$. pylori. Despite this fact, less than $2 \%$ of the patients develop gastric cancer [3]. Although many factors may be related to $H$. pylori associated gastric carcinogenesis, the underlying molecular mechanisms are still unknown. The complications of chronic inflammation associated with H. pylori infection are believed to be related to the genetic features of the host, virulence factors of the bacteria strain, and environmental factors [4]. Telomerase, located at the distal end of human chromosomes, comprises simple, repetitive and G-rich hexameric sequences (TTAGGG), and is vital for chromosomal stability and replication [5]. Short telomeres are associated with cellular senescence and decreased tissue renewal capacity [6]. Longer telomere length (TL) appears to prevent genomic instability and development of cancer in human aged cells by limiting the number of cell divisions. However, shortened telomeres impair immune function that might also increase cancer susceptibility [7]. Telomere length has been analyzed in many human cancers, and it has been found to be shorter in some tumors 
(e.g. colon cancer, gastric cancer and glioblastoma) and longer in others (e.g. chordoma) compared to normal tissue $[8,9]$. In this study we aimed to assess the absolute (TLs) in gastric mucosa of $\mathrm{H}$. pylori positive patients compared to $\mathrm{H}$. pylori negative controls and to determine any changes in (TLs) by H. pylori eradication therapy.

\section{PATIENTS AND METHODS}

\section{Patients:}

This cohort prospective study was carried out in the Hepatology, Gastroenterology and Infectious Diseases and Medical Microbiology and Immunology Departments, Faculty of Medicine, Benha University from January 2016 to July 2016. The study was approved by the local ethics committee of Benha University Hospitals and written consent was taken from each participant. Forty two adult patients were enrolled in this study were complaining of dyspeptic symptoms (defined as abdominal pain related to the meals). According to the results of upper GIT endoscopy, biopsy urease test and microbiological culture, selected patients were divided into 2 groups. Group I: (17) $H$. pylori negative patients with functional dyspepsia (according to Rome II criteria) [10] and they were considered as a control group. Group II: (25) $H$. pylori positive patients. Patients with chronic disease as liver cirrhosis, chronic renal failure, diabetes, hypertension, obstructive airway diseases, patients with history of non-steroidal anti-inflammatory drugs (NSAIDs), proton pump inhibitors (PPI) within previous month, heavy smokers and patients with cancers were excluded from the study.

All patients were subjected to full history taking, thorough clinical examination and routine laboratory investigation.

Upper GIT endoscopy: was done for all patients and controls by the same endoscopist after fasting at least 8 hours using video endoscope (OLYMPUS GIF TYPE Q180 2001629, Japan). Four quadrant biopsies were taken from antral mucosa within $5 \mathrm{~cm}$ of the pyloric opening for detection of $H$. pylori infection using urease test and microbiological culture and TL analysis. In positive $H$. pylori cases upper GIT endoscopy was repeated one month after $H$. pylori eradication therapy (a full dose PPI, Clarithromycin $500 \mathrm{mg}$ and Metronidazole $400 \mathrm{mg}$, all twice daily for 2 weeks) and biopsy samples were again taken to determine the changes in telomere length after eradication therapy, gastric fragments were kept in thioglycolate broth (Difco Laboratories, Detroit, Mich.) at $4^{\circ} \mathrm{C}$. Samples for TL analysis were sent to the laboratory in tubes with $0.9 \%$ $\mathrm{NaCl}$. Then they were centrifuged at $3000 \mathrm{~g}$ for 5 minutes, the supernatant was removed, and the tissue samples were stored at $-80^{\circ} \mathrm{C}$ until $\mathrm{TL}$ was analyzed using (RT.PCR).

\section{Identification of $\boldsymbol{H}$. pylori}

Urease test: Biopsies were placed in tubes containing christensen's $2 \%$ urea agar and examined within $24 \mathrm{~h}$ of incubation at $37^{\circ} \mathrm{C}$ for urea hydrolysis.

Microbiological Culture: Fragments in thioglycolate broth (Difco Laboratories, Detroit, Mich.) were ground in a tissue homogenizer. Biopsies were rubbed onto Dent's agar plates using Columbia agar base supplemented with $7 \%$ human blood containing vancomycin, trimethoprim, cefsulodin and amphotercin B (Oxoid, Basingstoke, United Kingdom). Plates were incubated for 4-7 days in microaerophilic environment at $37^{\circ} \mathrm{C}$. Bacteriological identification of $H$. pylori was done. Patients considered positive for $H$. pylori if direct urease and culture were positive or if culture alone was positive and considered negative if both tests were negative [11].

Genomic DNA extraction: DNA was extracted using QIAamp DNA mini kit (Qiagen, Germany) according to the manufacturer instructions. The extracted DNA concentration was confirmed through measurement by NanoDrop 2000c Spectrophotometer. Readings were taken at wave lengths of 260 and $280 \mathrm{~nm}$. Concentration of DNA samples were measured $=30 \mathrm{ng} / \mu \mathrm{L}$ at wave lengths 260 and $280 \mathrm{~nm}$ [12].

Quantitative real time PCR: as described by Cawthon [13].

\section{Telomere length assay}

Telomere and human $\beta$ - Globin (HBG) gene were analyzed on DNA samples in 36-well rotor (Rotor-Gene Q 5plex. Qiagen, Germany) using Rotor-Gene_2_3_1_software.

HBG was used as a single copy gene needed for normalization. Necessary standards for absolute quantitation of $\beta$-globin expression were prepared using QuantiTect SYBR Green PCR Kit (Roche, Germany).

The telomere length assay was performed according to manufacturer's instructions with a Telo TAGGG Telomere Length Assay (Roche, Germany) kit. The product derived from the 
telomere PCR assay was normalized with the product obtained by the $\beta$-globin PCR assay and telomere length was measured in base pairs (bp). The primers used in amplifications were described in table1.

Cycling conditions (for both telomere and HBG amplicons) are: $10 \mathrm{~min}$ at $95^{\circ} \mathrm{C}$, followed by 40 cycles of $95^{\circ} \mathrm{C}$ for $15 \mathrm{sec}, 60^{\circ} \mathrm{C}$ for $1 \mathrm{~min}$, followed by a meltingcurve analysis.

A plot of CT (the fractional cycle number at which the well's accumulating fluorescence crosses a set threshold that is several standard deviations above baseline fluorescence), versus $\log$ (amount of input target DNA) was generated by performing serial dilutions of the standards ranging between $10^{-1}$ to $10^{-6}$ dilution. This linear curve allows absolute quantitation of unknowns in the same PCR run.

\section{Statistical analysis:}

Collected data were analyzed using SPSS 16 (SpssInc, Chicago, ILL Company). Categorical data were presented as number and percentages while quantitative data were expressed as mean \pm standard deviation, and range. Chi square test (X2) test was used to analyze categorical variables. Quantitative data were tested for normality using KolomogrovSmirnove test, using Wilcoxon test, Man Whitney $\mathrm{U}$ test and Spearman's correlation coefficient (rho) as proved to be non-parametric. $\mathrm{P}<0.05$ was considered significant.

Table (1): Primer sequences in amplification reaction [13]

\begin{tabular}{|l|l|l|}
\hline \multirow{2}{*}{ Gene } & \multicolumn{1}{|c|}{ Forward } & \multicolumn{1}{|c|}{ Primers } \\
\cline { 2 - 3 } THR $^{*}$ & $\begin{array}{l}\text { 5'GGTTTTTGAGGGTGAGGGTGAGGGTGAGGGT } \\
\text { GAGGGT-3' }\end{array}$ & $\begin{array}{l}\text { 5'TCCCGACTATCCCTATCCCTATCCCTATCCC } \\
\text { TATCCCTA-3' }\end{array}$ \\
\hline HBG $^{* *}$ & 5'-GCTTCTGACACAACTGTGTTCACTAGC-3' $^{\prime}$ & 5'-CACCAACTTCATCCACGTTCACC-3' \\
\hline
\end{tabular}

THR telomere hexamer repeats.

$\mathrm{HBG}^{* *}$ human $\beta$-globin.

\section{RESULTS}

This cohort prospective study was conducted on $25 \mathrm{H}$. pylori-positive patients (16 males and 9 females) with mean age $39.4 \pm 8.12$ years and 17 H. pylori- negative patients served as a control group (12 males and 5 females) with mean age $38.5 \pm 8.5$ years. There was insignificant statistical difference between patients and controls as regard sex and age, $(\mathrm{P}$ value $=0.65$ and 0.74 respectively) (Table 2 ).

The absolute TLs was shorter in $H$. pylori positive patients than control group (H. pylori negative patients) before treatment regimen (2326.4 \pm 165.06 bp Vs $3046.7 \pm 331.60$ bp respectively) with highly statistically significant difference between both groups $(\mathrm{P}<0.001)$ (Table 3$)$.

In Table (4) there was highly statistically significant difference between $H$. pylori positive patients before and after eradication therapy $(\mathrm{P}<0.001)$. The telomere length was significantly increased after eradication therapy (absolute TLs was $2326.4 \pm 165.06$ bp before treatment Vs $2842.3 \pm 296.04$ bp after treatment).

There was insignificant difference in absolute TLs in $H$. pylori positive patients after eradication therapy compared to control group $(\mathrm{P}=0.053)$ (Table 5).

There was significant negative correlation between ages of patients and TLs before and after treatment (before treatment, $\mathrm{r}=-0.713, \mathrm{P}<0.001$, after treatment $\mathrm{r}=-0.846, \mathrm{P}<0.001$ ) (Figs. 1,2 respectively). While as regard the relation between sex and TLs there was no significant relation (before treatment TLs in males was $2335.5 \pm 166.97 \mathrm{bp}$, in females it was $2310.1 \pm$ $170.28 \mathrm{bp}$ and $\mathrm{P}$ value $=0.51$ and after eradication therapy TLs was in males $2881.6 \pm$ $305.00 \mathrm{bp}$ and in females it was $2772.3 \pm 282.65$ bp with $\mathrm{P}$ value $=0.55)($ Table 6$)$. 
Table (2): Comparison between studied groups regarding sex and age

\begin{tabular}{|l|c|c|l|c|}
\hline \multicolumn{1}{|c|}{ Variable } & $\begin{array}{c}\text { Group I }(\mathbf{N}=\mathbf{1 7}) \\
\text { H. pylori negative cases }\end{array}$ & $\begin{array}{c}\text { Group II }(\mathbf{N}=\mathbf{2 5}) \\
\text { H. pylori positive cases }\end{array}$ & Test & $\begin{array}{c}\text { P } \\
\text { value }\end{array}$ \\
\hline Sex & $\begin{array}{c}5(29.4) \\
\text { Females (\%) }\end{array}$ & $\begin{array}{c}9(36.0) \\
16(64.0)\end{array}$ & $\mathrm{X}^{2}=198$ & 0.65 \\
Males (\%) & $12(70.6)$ & $\begin{array}{c} \\
(25.4 \pm 8.12\end{array}$ & $\mathrm{t}=0.32$ & 0.74 \\
\hline $\begin{array}{l}\text { Age (years) } \\
\text { Mean } \pm \text { SD; } \\
\text { (range) }\end{array}$ & $\begin{array}{c}38.5 \pm 8.5 \\
(25-52)\end{array}$ & & & \\
\hline
\end{tabular}

Table (3): Comparison between H. pylori positive patients and control group as regard TLs before treatment

\begin{tabular}{|c|c|}
\hline \multirow{2}{*}{ Study groups } & TLs*in bp \\
\cline { 2 - 2 } & Mean \pm SD \\
\hline H. pylori $* *$ positive patients before treatment (No.=25) & $2326.4 \pm 165.06$ \\
\hline H. pylori $* *$ i negative control group (No.=17) & $3046.7 \pm 331.60$ \\
\hline Test & $* * *$ MWU Z $=5.25$ \\
\hline P value & $<\mathbf{0 . 0 0 1}$ \\
\hline
\end{tabular}

*Telomere length, **Helicobacter pylori, ***MWU= Man Whitney U Test

Table (4): TLs in H. pylori positive patients before and after eradication therapy

\begin{tabular}{|c|c|}
\hline $\begin{array}{c}\text { Study groups } \\
(\text { No.=25) }\end{array}$ & TLs*in bp \\
\cline { 2 - 2 } & Mean \pm SD \\
\hline H. pylori** positive patients before eradication therapy & $2326.4 \pm 165.06$ \\
\hline H. pylori** positive patients after eradication therapy & $2842.3 \pm 296.04$ \\
\hline Test & Wilcoxon test Z Z=4.4 \\
\hline P value & $<\mathbf{0 . 0 0 1}$ \\
\hline
\end{tabular}

*Telomere length, **Helicobacter pylori.

Table (5): Comparison between H. pylori positive patients and control group as regard TLs after eradication therapy

\begin{tabular}{|c|c|}
\hline \multicolumn{1}{|c|}{ Study groups } & TLs* \\
\cline { 2 - 2 } & Mean \pm SD \\
\hline H. pylori $* *$ positive patients after eradication therapy (No.=25) & $2842.4 \pm 296.04$ \\
\hline H. pylori** negative control group (No.=17) & $3046.7 \pm 331.60$ \\
\hline test & MWU Z $=1.93$ \\
\hline P value & 0.053 \\
\hline
\end{tabular}




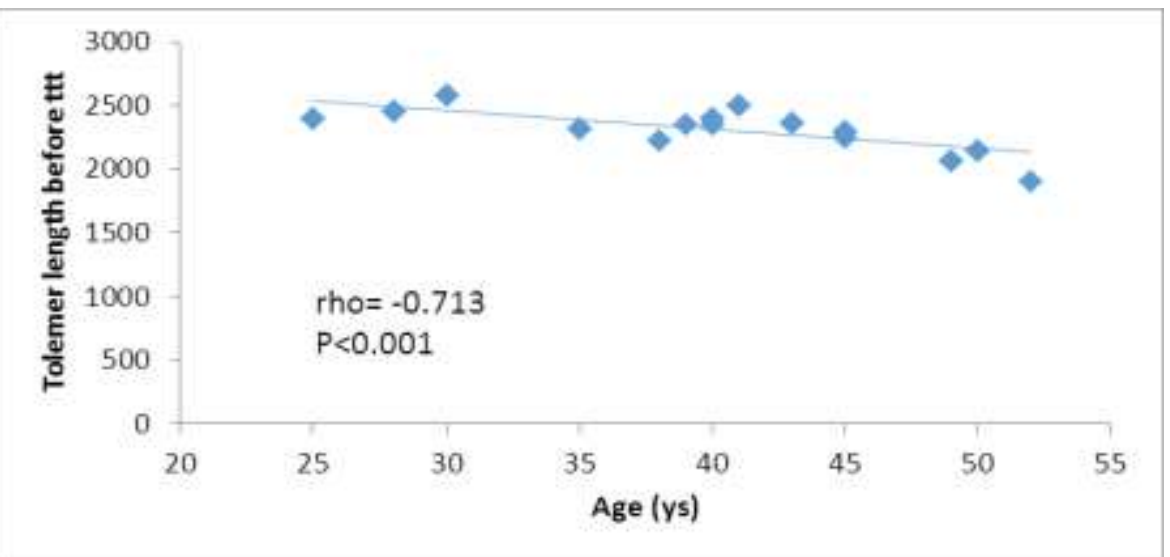

Figure (1): Correlation between age and telomere length before treatment

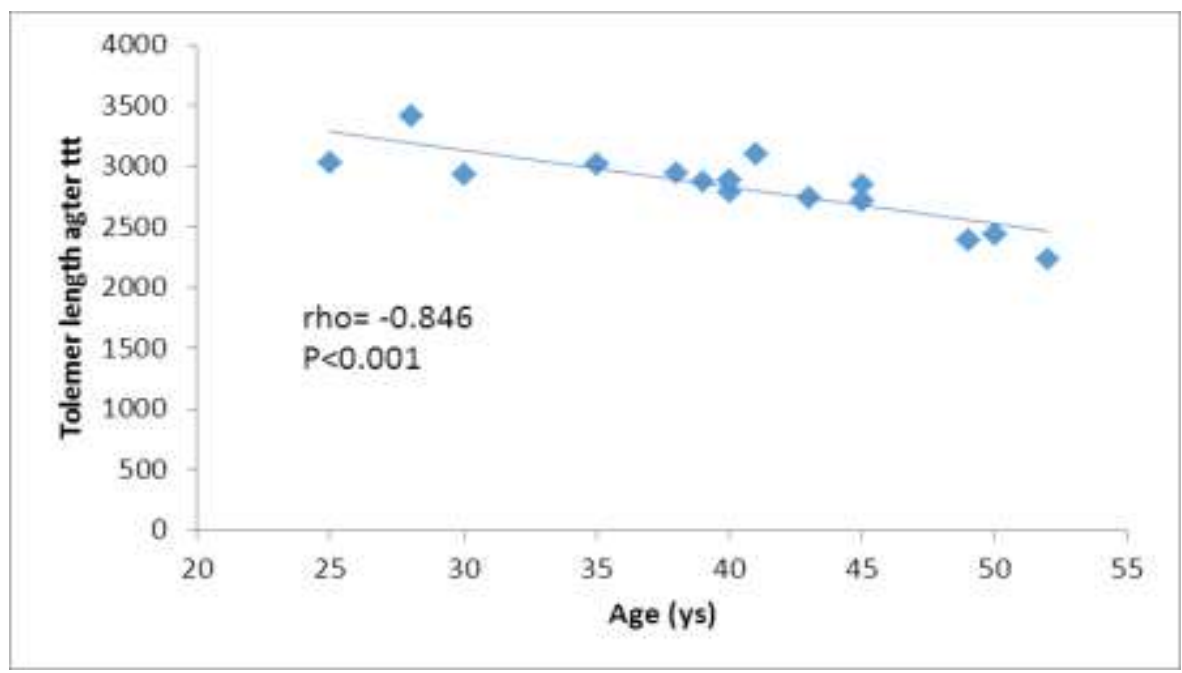

Figure (2): Correlation between age and telomere length after treatment

Table (6): Relation between sex and telomere length

\begin{tabular}{|l|c|c|c|}
\hline \multicolumn{1}{|c|}{ Sex } & Telomere length $($ bp) Mean \pm SD & Test & P value \\
\hline $\begin{array}{l}\text { Before eradication therapy } \\
\text { Male }(\mathrm{N}=16)\end{array}$ & $2335.5 \pm 166.97$ & MWU & \multirow{2}{*}{0.51} \\
Female $(\mathrm{N}=9)$ & $2310.1 \pm 170.28$ & $\mathrm{Z}=0.65$ & \\
\hline After eradication therapy & & & \\
Male $(\mathrm{N}=16)$ & $2881.6 \pm 305.00$ & $\mathrm{MWU}$ & 0.55 \\
Female $(\mathrm{N}=9)$ & $2772.3 \pm 282.65$ & $\mathrm{Z}=0.59$ & \\
\hline
\end{tabular}




\section{DISCUSSION}

Telomeres are special chromatin structures that protect the ends of chromosomes from degrading and restructuring activities [4]. They consist of repetitive nucleotide sequences and an associated terminal protein complex that is vital for chromosomal stability, replication and prevent loss of chromosomal integrity [5]. Telomere shortening results in the deterioration of the protective functions, fusion in chromosomes, breaking and bridging, and gene amplifications. All of which lead to genomic instability, the most significant feature of solid tumors [14]. Inflammation, oxidative stress and increased cell replication are major environmental factors associated with accelerated shortening of telomeres [15]. Meta-analyses suggest 1.4 to 3.0 fold increased risk of cancer for those with the shortest versus longest telomeres [16,5]. $H$. pylori infection in gastric mucosa leads to chronic inflammation and complications, such as ulcer, metaplasia and cancer. Even though the relation of $H$. pylori and the pathogenesis of gastric cancer is not completely known, it has been shown that a change in telomere length and telomerase activity in pre-neoplastic and cancerous tissue might arise. This change is considered a stage or cause in the development of cancer [17]. Pre-neoplastic changes that might progress into gastric cancer are found in around $50 \%$ of people infected with $H$. pylori and TL has been found to be shorter in some tumors a scolon cancer and gastric cancer compared to normal tissue $[8,9]$. This study was performed to assess the absolute TLs in gastric mucosa of $H$. pylori infected patients compared to $H$. pylori negative controls and determine the effect of eradication of $H$. pylori infection on TLs. In the present study we found highly significant shortening in TLs in $H$. pylori positive patients than control group $(\mathrm{P}<0.001)$, this finding was in agreement with Kuniyasu et al. [18]. Who reported that TL was significantly shorter in the group infected by $H$. pylori than in the uninfected group, in the same hand Aida et al. [19] demonstrated that $H$. pylori-positive gastric mucosa has been shown to have shorter TL than H. pylori negative mucosa. Similarly Aslan et al. [20] found that the telomere length was found to be $2958.9 \pm 1345.7 \mathrm{bp}$ in the control group and $2481.2 \pm 1823 \mathrm{bp}$ in the study group prior to eradication; however, this difference was not significant ( $\mathrm{p}=0.11)$. In the present work, after $H$. pylori eradication therapy, there was highly statistically significant elongation in TLs in $H$. pylori positive cases $(\mathrm{P}<0.001)$, that in agreement with Aslan et al. [20] who found that The telomere length was found to be $3766.3 \pm$ $1608.8 \mathrm{bp}$ in the study group after eradication. In this group, the telomere length was significantly increased after eradication compared to the period before eradication $(\mathrm{p}=0.01)$, and considered this finding provides new approach for effectiveness of $H$. pylori eradication therapy in increasing the TLs and decrease incidence of gastric cancer, also Chung et al. [5] elucidated that peptic ulcer and intestinal metaplasia are closely related to $H$. pylori infection. Furthermore, chronic gastritis due to $H$. pylori infection may progress to intestinal metaplasia and even gastric cancer. This finding was considered to provide the effectiveness of $H$. pylori eradication therapy in increasing the TLs and decrease incidence of gastric cancer. Also in the present study we found significant negative correlation between age and absolute TLs in patients group before and after treatment $(\mathrm{P}<0.001)$, this result disagreement with Aslan et al. [20] who found negative correlation but insignificant $(r=0.172$, $\mathrm{p}>0.05)$, while Hou et al. [21] reported that telomeres were significantly shorter in association with aging $(\mathrm{P}<0.001)$, and the extent of telomere shortening may vary considerably among individuals within age groups, suggesting that environmental and lifestyle factors could play critical roles in the rate of telomere attrition. As regard relation between TLs and sex the present work found insignificant relation between TLs and gender before eradication therapy in patients group $(2335.5 \pm 166.97 \mathrm{bp}$ in males and $2310.1 \pm$ 170.28 bp in female with $P$ value 0.51 ) this in agreement with Aslan et al. [21] as they found TLs before eradication was found (2721.3 \pm $2003.44 \mathrm{bp}$ in males, $2161.1 \pm 1608.6 \mathrm{bp}$ in females, $\mathrm{p}>0.05)$, on the same hand Hou et al. [21] reported insignificant relation between TLs and sex $(\mathrm{P}$ value $=0.09)$, when studying TLs in gastric cancer related to $H$. pylori positivity.

\section{CONCLUSION}

H. pylori positive patients have significantly shorter absolute TLs in their gastric mucosa compared to $H$. pylori negative controls. $H$. pylori eradication therapy increases the absolute TL in $H$. pylori infected patients and that can open new approach for consider effectiveness of $\mathrm{H}$. pylori eradication therapy in increasing the telomere length one of preventable methods for gastric cancer. 


\section{Funding: None.}

\section{Conflicts of interest: None.}

Ethical approval:Approved.

\section{REFERENCES}

1. Suerbaum S, Michetti P: Helicobacterpylori infection. N Engl J Med 2002; 347:1175-1186.

2. Fuchs CS, Mayer RJ. Gastric carcinoma. N. Engl. J. Med. 1995;333: $32-41$.

3. Correa P. Human gastric carcinogenesis: a multistep and multifactorial process. First American Cancer Society Award Lecture on Cancer Epidemiology and Prevention. Cancer Res 1992; 52:6735-6740.

4. Helicobacter, Cancer Collaborative Group: Gastric cancer and Helicobacter pylori: A combined analysis of 12 case control studies nested within prospective cohorts. Gut 2001; 49:347-353.

5. Chung K, Hwang KY, Kim IH, Kim HS, Park $\mathrm{SH}$, Lee $\mathrm{MH}$, et al. Helicobacter pylori and Telomerase Activity in Intestinal Metaplasia of the Stomach. Korean J Intern Med. 2002; 17(4): 227-33.

6. Vulliamy T, Marrone A, Dokal I, Mason PJ. Association between aplastic anaemia and mutations in telomerase RNA. Lancet. 2002; 359(9324):2168-70.

7. Eisenberg DTA. An evolutionary review of human telomere biology: The thrifty telomere hypothesis and notes on potential adaptive paternal effects. American Journal of Human Biology.2011; 23 (2): 149-67.

8. Wentzensen IM, Mirabello L, Pfeiffer RM, Savage SA. The association of telomere length and cancer: a meta-analysis. Cancer Epidemiol Biomarkers Prev 2011; 20:1238-1250.

9. Mu Y, Zhang Q, Mei L, Liu X, Yang W, Yu J. Telomere shortening occurs early during gastrocarcinogenesis. Med Oncol 2012; 29:893898.

10. Thompson WG, Longstreth GL, Drossman DA. The functional bowel disorders in: Drossman DA. Corazziarie E, Talley NJ, Whitehead WE, eds. Room II: The functional Gastrointestinal disorders. Diagnosis Pathophysiology and treatment. A multinational Consensus. Lawerence, KS: Allen Press. 2000:1-31.

11. Rocha GA, Oliveira AM, Queiroz DM, Carvalho AS, Nogueira AM. Immunoblot analysis of humoral immune response to Helicobacter pylori in children with and without duodenal ulcer. $J$ ClinMicrobiol. 2000; 38 (5):1777-81.
12. Alhusseini NF, Ali AI, Abul-Fadl AMA, AbuZied AA, El-Taher SM. Gene expression of FADS2 mRNA linked to intelligence in exclusively breast milk fed preterms. Am. J. Biochem. Biotechnol.2014; 10: 267-74.

13. Cawthon RM. Telomere measurement by quantitative PCR. Nucleic Acids Res. 2002; 30:e47.

14. Callen E, Surrallés J. Telomere dysfunction in genome instability syndromes. Mutat Res. 2004; 567(1): 85-104.

15. Von Zglinicki T. Oxidative stress shortens telomere. Trends Biochem Sci. 2002; 27(7):33944.

16. Ma H, Zhou Z, Wei S, Liu Z, Pooley KA, Dunning AM, et al. Shortened telomere length is associated with increased risk of cancer: a metaanalysis. PLOS ONE. 2011; 6 (6): e20466.

17. Avilion AA, Piatyszek MA, Gupta J, Shay JW, Bacchetti S, Greider CW. Human telomerase RNA and telomerase activity in immortal cell lines and tumor tissues. Cancer Res 1996; 56:645-650.

18. Kuniyasu H, Kitadai Y, Mieno H, Yasui W. Helicobacter pylori infection is closely associated with telomere reduction in gastric mucosa. Oncology. 2003; 65(3):275-82.

19. Aida J, Izumiyama-Shimomura N, Nakamura K, Ishii A, Ishikawa N, Honma N, et al. Telomere length variations in 6 mucosal cell types of gastric tissue observed using a novel quantitative fluorescence in situ hybridization method. Hum Pathol. 2007; 38(8):1192-200.

20. Aslan R, Bektas A, Bedir A, Alacam H, Aslan MS, Nar R, et al. Helicobacter pylori eradication increases telomere length in gastric mucosa. Hepatogastroenterology. 2013; 60(123):601-4.

21. Hou L, Savage SA, Blaser MJ, Perez-Perez G, Hoxha M, Dioni $\mathrm{L}$ et al. Telomere length in peripheral leukocyte DNA and gastric cancer risk. Cancer Epidemiol Biomarkers Prev. 2009; 18(11):3103-9.Llovet : Gastroenterology; 2005, $20(1): 4-5$.

Peer reviewers: Dr. Nahla Elgammal, Professor of Tropical Medicine, Faculty of Medicine, Zagazig University, Egypt. Dr. Usama Mazid. Department of Medicine, Alyousef Hospital, Khobar, Saudi Arabia.

Editor: Tarik Zaher, Professor of Tropical Medicine, Faculty of Medicine, Zagazig University, Egypt 